\title{
PREFACE to the First Printing
}

My study of Okinawan religion commenced in 1953-54 (September to June) during nine months of field research under the auspices of the Pacific Science Board of the National Research Council. From October of 1955 through August of 1957 I divided my time between Japan and the Ryukyu Islands, continuing field studies in the latter area and studying relevant literature available in Japan. In January of 1960 I returned to Okinawa and remained until August under a research grant (M-3084) from the National Institute of Mental Health. Finally, a brief trip was made in September and October, 1961, for the purpose of following up certain aspects of the 1960 research. Aside from minor changes, this manuscript was completed by the end of 1961.

The primary intent of this study has been to present a systematic, descriptive account of the indigenous religion of Okinawa. By "indigenous religion" I mean those beliefs, practices, and organizations constituting the autochthonous system rather than such religions as Buddhism and sectarian Shinto which have developed elsewhere and have remained coherent, recognizably foreign imports. This does not imply that Okinawan religion has evolved independently of any external influences, for quite the contrary can be shown to be the case. Numerous Buddhist concepts and practices, elements of Chinese folk religion, and resemblances to Shinto are easily detected; furthermore, this borrowing has been a long and cumulative process, one that continues to this day. There remain, nonetheless, many traits which appear to be purely local, and these as well as those of foreign origin have been integrated into a configuration unique to Okinawa and its neighbor islands. It is with this system that we shall be concerned. 
A secondary focus relates to the process of change within a given historic context. Utilizing elderly informants and written sources, I have attempted to reconstruct the system as it was in the last quarter of the nineteenth century and to use this material for comparative purposes when describing the contemporary religion. During the lifetime of the oldest generation, Okinawa has been subject to extensive cultural, social, and physical changes of such magnitude that virtually no aspect of life or scene has escaped unaltered. Three governments-those of the Ryukyuan Kingdom, Japan, and the United States military occupation-have successively administered the area during the past eighty years; each has been the product of a different culture and marked by radically different programs and administrative objectives. World War II culminated in a catastrophic invasion which served to accelerate the process of change. Traditionally, Okinawan religion has been characterized by a collectivity focus; its main foci have been the state, community, kin group, and family-household. The advent of Japanese administration effected the collapse of the Ryukyuan state and state religion, but the community, kin group, and family have managed to preserve their ritual integrity with varying degrees of success until the present time. A marked decline in religious activities has occurred during the past fifty years, accompanied by the gradual emergence of individualism in contrast to the traditional emphasis on communalism and familialism. In the light of these changes, the persistence of certain aspects of the religious system and the rapid disappearance of others warrant our attention.

An ideal-type analysis has been followed throughout. Several factors necessitated selection of this method, the principal one being that it best served the objective of treating Okinawan religion as a total system while allowing variations to be gauged against the total construct. The process of change has not been uniform throughout the islands. Therefore, an attempt to amplify the religion of any given community, kin group, or household as representative of the whole would be misleading. For example, the presence or absence, support or nonsupport, of religious ceremonies within a given community has been determined by a variety of factors. Rural settlements of gentry origin have always been without formalized community ritual, while in many commoner villages that formerly had an active religious life, the death of the hereditary priestess(es) in the war brought an abrupt end to all communal rites. In other villages, 
though the priestess may still be alive, want of support by acculturated political leaders often precludes her enjoying any significant, active role. Fishing villages have retained a stronger emphasis on community religion than farming villages, while both decidedly exceed the towns and cities in this respect. One further reason has been that I have drawn heavily on written sources to supplement field data; these materials have been obtained from widely scattered areas of the island, still older unpublished manuscripts, and a variety of informants and observers. Here, any approach other than the ideal-type would simply have been impracticable.

Field data were gathered in all parts of Okinawa, from informants in more than one hundred communities ranging in size from Naha, the capital, down to small hamlets. ${ }^{1}$ The major approach in field research was the interview, although the usual corollary techniques of observation, copying records, photographing, recording, mapping, etc., were also employed. I found that Okinawans tended to respond unfavorably to persistent direct questioning, as in following a rigid interview schedule or questionnaire. Consequently, most interviews were of the open-end type-when a given subject had been introduced, the informant was not unduly pressured by a barrage of predetermined questions but was allowed considerable freedom in discourse. No professional informants were employed, and no informants were paid for their services, although small gifts of food or tobacco were sometimes made. During the 1960 and 1961 field trips virtually all interviews were recorded.

Japanese and Okinawan were the languages of interviewing, and the services of an interpreter were employed. Most Okinawans today are bilingual, speaking Japanese and Okinawan, but the very old use the native language almost exclusively, while most country women appear to do so by preference. Not infrequently, discussion initiated in Japanese would lapse into Okinawan, for the simple reason that many informants were more articulate in the latter. In this study, Okinawan terms have been preserved wherever a given concept, practice, status, or item has proved sufficiently important to warrant distinction and/or defy accurate translation. The system of orthography followed is described in the Note on Foreign Words appearing on page xiv.

Source material on Okinawan religion in Western literature tends to be meager and superficial. Turning to Japanese sources, one is confronted not by a lack of material but rather by an absence of systemic approach. 
For the most part, Japanese researchers have been of the folklorist (or more properly Volkskunde) school-usually students or disciples of Yanagita Kunio. The Okinawan contributors have been largely amateur folkhistorians. Commonly, the writings of these individuals have been based on very brief periods of field research (more in the nature of tours than protracted field studies), on personal reminiscences, or on the interpretation of old Okinawan literature. Japanese scholars early recognized many similarities between Okinawan religion and ancient Shinto; thus, for not a few the sole attraction of the former has been its significance with regard to the latter. In most studies the frame of reference has been Okinawan religion and culture vis-aे-vis Japanese religion and culture. Use of comparative material from Taiwan, China, and Korea has been conspicuously absent. Excessive reliance on old literature and a lack of extensive field research have tended to produce studies which are either highly subjective and speculative or simply catalogues of the more obvious facets of this culture. The usefulness of such research has been further impaired by a steadfast refusal or inability to record Okinawan words as spoken. In virtually all studies save those of the linguists Hattori and Kinjō, Okinawan terms have been persistently Japanized; one must decode 'okode' into ukudii, 'noro' into nuru, 'nebito' into niitchu, and so on. Failure to check written data against the knowledge and speech of living informants not infrequently has produced ludicrous results. For example, the title of the chief priestess is regularly rendered as 'kikoe o gimi' in Japanese, but use of this title invariably elicits a blank response from informants, who are accustomed to the Okinawan chifjing ganashii mee. Much of the usual vocabulary of "native terms" is, consequently, without meaning in Japanese or Okinawan. If the nonspecialist reader feels inundated by native terms in my study, it should be remembered that I have tried to compensate for errors of the past and to ease the task of field workers to follow. No aspect of Okinawan research, however, can be undertaken without recourse to Japanese sources; I have merely sought here to indicate some of their limitations. Their usefulness will be attested by the frequency of citation.

During the past few years I have been amused by certain seemingly astute observers who have commented on the lack of religion among Okinawans. Basil Hall Chamberlain noted, "No country that I have ever visited shows scantier evidence of active religious influence than Loochoo,"2 
and not too long ago an American official on Okinawa remarked to me that, insofar as religion is concerned, "They haven't got any!" These points of view, at least, should be dispelled by this study. But an opposite situation may arise when one immerses himself in the religion of a particular people, as I have attempted, and that is the tendency to discern evidences of religion almost everywhere. Lest the reader unfamiliar with Okinawa gain the impression that these people are decidedly "otherwordly," I would like to repeat Allport's comment that, chronologically, viscerogenic or "bodily" values take precedence over psychogenic or "spiritual" values. ${ }^{3}$

My indebtedness extends to many people and institutions. The Pacific Science Board, the National Institute of Mental Health, and my parents have sustained me while in the field. The University of Pittsburgh twice granted a release from all teaching duties, and the East-West Center of the University of Hawaii provided me with support while writing. Further benefit was gained from colleagues of the first field trip, Drs. Forrest $\mathbf{R}$. Pitts of the University of Hawaii and Wayne P. Suttles of the University of Nevada, with whom the exchange of ideas often provided insights which widened the scope of my research. Special appreciation must be accorded Mr. Kiyoshi Yogi of Naha, who functioned as field assistant, interpreter, and companion, and who did much to facilitate the progress of my research. Mr. Teruo Tanonaka of the United States Civil Administration gave freely of his hospitality and broad knowledge of the area on occasions too frequent to enumerate, and Mr. Dale Lock of Canada Dry of Okinawa frequently solved my transportation problems by loaning me his car. Lastly, my sincerest gratitude extends to innumerable Okinawans whose keen interest and kindly patience with the often trying questions of an outsider contributed so much to make the periods of field study both enjoyable and rewarding. Responsibility for the accuracy of data and conclusions derived therefrom, however, rests solely upon myself. 
